\title{
PHYTOCHEMICAL AND ANTIOXIDANT PROPERTIES OF VARIOUS EXTRACTS OF MICHELIA CHAMPACA LEAVES
}

\author{
PUSHPA RUWALI*, MAMTA ADHIKARI, SUBHANSHI SHARMA
}

Department of Biotechnology, M. B. Government P. G. College Haldwani 263139 Uttarakhand, India

Email: pushparuwali@gmail.com

Received: 28 Dec 2018 Revised and Accepted: 06 Apr 2019

\begin{abstract}
Objective: To investigate and compare the phytochemicals, antioxidant activities of various crude extracts from fresh leaves of locally available plant Michelia champaca belonging to family Magnoliaceae.

Methods: The present study was designed to perform preliminary phytochemical (qualitative and quantitative) analysis of various extracts. The crude extracts from the leaves of M. champaca were prepared using various organic solvents viz. Methanol (MCMET), Ethanol (MCETH), Hexane (MCHEX), and Chloroform (MCCHLO). In addition, total phenolic (TPC) and total flavonoid (TFC) contents of various extracts were also measured along with the evaluation of the antioxidant capacities using most widely accepted in vitro chemical tests such as DPPH and ABTS radical scavenging assay.

Results: The methanolic extract of $M$. champaca showed the presence of maximum phytochemicals (12) when compared to other solvent extracts viz. Hexane (10), Ethanol (8) and Chloroform(7). The amount of phenolic and flavonoids present in solvents were in the order of Methanol $>$ Hexane $>$ Ethanol $>$ Chloroform. The best antioxidant potential was found in the Methanol extract. The Methanolic extract exhibited an IC 50 value of $72.03 \mu \mathrm{g} / \mathrm{ml}(\mathrm{DPPH})$ and of $185.21 \mu \mathrm{g} / \mathrm{ml}$ (ABTS), respectively for the two radical scavenging assays.

Conclusion: Phytochemical analysis of M. champaca (leaves) various extracts showed good amounts of phenolic and flavonoid contents and also exhibited significant antioxidant activity. A positive linear correlation between the antioxidant activities and the total phenolic and flavonoid contents of the plant extracts was observed. Study revealed variations in such reported activities due to different organic extraction solvents used. In overall conclusion, Michelia champaca has good potential as a source of natural antioxidant for animal health and food industry and further
\end{abstract} relevant studies on similar lines would be worthwhile.

Keywords: Michelia champaca, Phytochemicals, Total Phenol, Flavonoids, Antioxidant activity

(C) 2019 The Authors. Published by Innovare Academic Sciences Pvt Ltd. This is an open-access article under the CC BY license (http://creativecommons.org/licenses/by/4.0/) DOI: http://dx.doi.org/10.22159/ijpps.2019v11i5.31745

\section{INTRODUCTION}

Medicinal plants are an integral part of our health care system and the most important source of life-saving drugs for the majority of the world's population. Since time immemorial man has been using plants as medicine for developing immunity or resistance against cold, joint pains, fever etc. Plants have been an important source of medicine for thousands of years. Even today, the World Health Organization estimates that up to 80 percent of people still rely mainly on traditional remedies [1]. More than $25 \%$ of pharmaceutical drugs across the world are derived from the plant's natural products [2].

Michelia champaca belongs to family Magnoliaceae is commonly known as Kanakchampa or Swarnachampa. It is abundant in the forests of the eastern sub-Himalayan tract and lower hills up to $3000 \mathrm{ft}$ MSL and also in Assam, Myanmar, South India, and the Western Ghats. In India, this plant is cultivated in gardens and near the temples for its fragrant flowers and handsome foliage. Its volatile oil is highly esteemed in perfumery. Its fruits and flowers are attributed to several properties [3].

The plant is tall, evergreen with straight stem and smooth brown bark. It is native to tropical and subtropical South and Southeast Asia. It holds commercial importance, especially, its flower from where essential oils are obtained so it has a useful application in perfumery, cosmetics, hair oil, and pharmaceutical industries. The plant is traditionally used for the treatment of cough, fever, colic, leprosy, and rheumatism and also helps in curing cephalalgia and ophthalmia [4]. The stem bark is febrifuge, stimulant, and expectorant and is useful in chronic gastritis, bronchitis, and cardiac debility. Root and root bark are purgative and emmenagogue and are useful in the treatment of constipation, amenorrhea, and dysmenorrhea. The fruits are used in dyspepsia and renal diseases and are effective in healing cracked feet $[5,6]$.

In spite of the abundance, utility in perfumery and pharmaceutical industry as well as ethnomedicinal importance of M. champaca, meager data is available on this important plant, especially on its antioxidant properties. The study being reported here was envisaged with the scientific intention of estimating the total phenolics and flavonoids and the in vitro free radicals scavenging potential of Michelia champaca leaves using various organic extraction solvents.

\section{MATERIALS AND METHODS}

\section{Chemicals and reagents}

Aluminium chloride ( $\mathrm{AlCl} 3)$, ascorbic acid (Vit $\mathrm{C})$, gallic acid $(3,4,5-$ trihydroxybenzoic acid), ferric chloride (FeCl3), Folin-Ciocalteu reagent, sodium bicarbonate (NaHCO3), sulphuric acid (H2SO4), hydrochloric acid $(\mathrm{HCl})$, acetic anhydride, chloroform $(\mathrm{CHCl} 3)$,alphanaphthol, ethanol, hexane, chloroform, methanol, sodium hydroxide $(\mathrm{NaOH})$, Fehling's A and B solutions, ninhydrin, Quercetin [2- $(3,4-$ dihydroxyphenyl)-3,5,7-trihydroxy-4H-chromen-4-one]. All these chemicals used in the study were purchased from SD Fine Chem. Pvt. Ltd. 2, 2 diphenyl 1 picrylhydrazyl (DPPH) and 2, 2'-azinobis (3ethylbenzothiozoline-6-sulfonic acid) diammonium salt (ABTS) was obtained from Sigma-Aldrich. All the chemicals and reagents were of analytical grade.

\section{Plant sample collection}

The samples (fresh leaves) were collected from Forest research institute, Haldwani, Nainital district of Uttarakhand state (India) in the month of February 2017, strictly abiding by the standard precautions. Identification of plant was done by the Botany Department (DSB campus), Kumaun University, Nainital, Uttarakhand (Ref. n. RKT-7941).

\section{Extraction of the plant material and yield calculation}

The freshly collected leaves of $M$. champaca were washed with clean potable water, the water was drained out immediately and the leaves were shade dried for the evaporation of the water present on the surface of the leaves. Next, the leaves were chopped into small 
pieces. These were shade dried for 3-4 d again to remove excess moisture. The completely dried leaves were ground in a mixer to obtain a fine homogeneous powder. The ground sample was further extracted by cold maceration for $72 \mathrm{~h}$ at $37{ }^{\circ} \mathrm{C}$ with occasional shaking with different solvents like methanol, hexane, chloroform and ethanol at ratio 1:10 (1 gm in $10 \mathrm{ml}$ solvent) to ensure complete extraction. After this, the extracts were filtered through Whatman ${ }^{\circledR}$ filter paper and the extracts were collected and stored at $4{ }^{\circ} \mathrm{C}$ in the refrigerator in an airtight container until further use $[7,8]$.

The percentage yield of various extracts of M. champaca was calculated by using the following formula

$$
\text { Percentage Yield }=\left(\mathrm{W}_{\mathrm{E}} \div \mathrm{W}_{\mathrm{S}}\right) \times 100
$$

Where $\left(\mathrm{W}_{\mathrm{E}}=\right.$ weight of the plant extract; $\mathrm{W}_{\mathrm{S}}=$ Weight of the initial sample)

Various extracts of $M$. champaca were subjected to preliminary phytochemical analysis, both qualitative as well as quantitative analysis as per standard methods.

\section{Qualitative phytochemical analysis of different crude extracts of $M$. champaca}

Extracts were tested for the presence of active principles such as carbohydrates, reducing sugars, amino acids, saponins, glycosides, flavonoids, tannins, sterols, triterpenes, and phenols following standard procedures [7-9].

\section{Preliminary quantitative phytochemical analysis of various extracts of M. champaca}

\section{Determination of total phenolics content}

The amount of phenolics in plant extract was determined by FolinCiocalteu reagent method of Singleton and Rossi, 1965 with slight modification [10]. The calibration curve was prepared by mixing different concentrations of Gallic acid $(1 \mathrm{ml} ; 20-120 \mu \mathrm{g} / \mathrm{ml})$ with $5 \mathrm{ml}$ of Folin-Ciocalteu reagent (ten-fold diluted) and $4 \mathrm{ml}$ of $\mathrm{Na}_{2} \mathrm{CO}_{3}$ $(7.5 \%)$. The absorbance of the sample was measured at $765 \mathrm{~nm}$. Gallic acid was used as a standard $(1 \mathrm{mg} / \mathrm{ml})$. All the tests were performed in triplicates. The results were determined from the standard curve and were expressed as mg Gallic acid equivalent (GAE)/gm of the leaves dried extract.

\section{Determination of total flavonoids content}

Aluminium chloride colorimetric method was used to determine flavonoid content. The total flavonoid content (TFC) was determined from the calibration curve of Quercetin and expressed as milligram of Quercetin equivalent per gram of dried leaves extract ( $\mathrm{mg} \mathrm{QE} / \mathrm{gm}$ of leaves dried extract). Total flavonoid content was determined according to the procedure of Zhishen et al.(1999) with slight modification [11]. $1 \mathrm{ml}$ of the plant extract was mixed with $1 \mathrm{ml}$ of methanol, $0.2 \mathrm{ml}$ of $10 \%$ aluminum chloride, $0.2 \mathrm{ml}$ of $1 \mathrm{M}$ potassium acetate and $5.6 \mathrm{ml}$ of distilled water were added and kept at room temperature for $30 \mathrm{~min}$. The absorbance was measured at $510 \mathrm{~nm}$. Quercetin was used as a standard $(1 \mathrm{mg} / \mathrm{ml})$. All the tests were performed in triplicates. Flavonoid contents were determined from the standard curve and were expressed as mg Quercetin equivalent $(\mathrm{QE}) / \mathrm{gm}$ of leaves dried extract.

\section{Evaluation of antioxidant activity}

\section{DPPH free radical scavenging assay}

The DPPH assay method is based on the reduction of DPPH $(2,2-$ diphenyl-1-picrylhydrazyl), a stable free radical was assessed by the standard method and adopted with suitable modification. When antioxidants react with DPPH, which is a stable free radical, it becomes paired off in the presence of a hydrogen donor (e. g., a free radicalscavenging antioxidant) and is reduced to the DPPH-H and as a consequence, the absorbance decreased from the DPPH. Radical to the DPPH-H form, resulted in decolorization (yellow colour) with respect to the number of electrons captured. When a solution ofDPPH is mixed with that of a substance that can donate a hydrogen atom, then this gives rise to the reduced form (Diphenylpicrylhydrazine; non-radical) with the loss of this violet colour [12].
DPPH radical scavenging method is a rapid and sensitive procedure to observe the antioxidant activity of plant extract. The free radicalscavenging activity of $M$. champaca leaves extracts were evaluated according to the method described by Blois (1958) and Ruwali et al. $(2017)[13,14]$ with some modifications. The stock solutions of the extracts were prepared in methanol to achieve the concentration of 1 $\mathrm{ml}$ of $0.2 \mathrm{mmol}$ DPPH solution. The dilutions were made to obtain concentrations $(25,50,100,200$ and $400 \mu \mathrm{g} / \mathrm{ml})$. A corresponding blank sample was prepared and Quercetin in different concentration was used as the reference standard. The experiment was performed in triplicate and the mixture was left for $30 \mathrm{~min}$ in the darkness at room temperature, and the absorbance was recorded at $517 \mathrm{nmusing}$ UV-Vis spectrophotometer. The inhibition $\%$ was calculated using the following formula.

Inhibition $\%=[(\mathrm{Ac}-\mathrm{As}) \div \mathrm{Ac}] \times 100$

Where 'Ac' is the absorbance of the control; 'As' is the absorbance of the sample

\section{ABTS free radical scavenging assay}

2, 2'-azinobis (3-ethyl benzothiazoline-6-sulfonic acid) diammonium salt (ABTS) assay measures the relative ability of an antioxidant to scavenge the ABTS generated in the aqueous phase, as compared with Ascorbic acid standard. The ABTS is generated by the reaction of a strong oxidizing agent (e. g., potassium permanganate or potassium persulfate) with the ABTS salt. Reduction of blue-green ABTS radical colored solution by hydrogen-donating antioxidant is measured by the suppression of its characteristic longwave (734 $\mathrm{nm}$ ) absorption spectrum [15].

For ABTS assay, the procedure followed was the method of Re et al.(1999)with some modifications [16]. ABTS radical cation (ABTS ${ }^{+}$) was obtained by reacting $\mathrm{ABTS}^{+}$stock solution with $2.45 \mathrm{mmol}$ potassium persulfate (final concentration) $(1 / 1, v / v)$ and allowing the mixture to stand in the dark for 12-16 h (hrs) before use. The $\mathrm{ABTS}^{+}$solution was diluted with ethanol to an absorbance of $0.700 \pm 0.05$ at $734 \mathrm{~nm}$ for measurements. The photometric assay was conducted on $0.9 \mathrm{ml}$ of ABTS+solution and $0.1 \mathrm{ml}$ of sample extract of various concentrations and mixed for $45 \mathrm{sec}$; measurements were taken immediately at $734 \mathrm{~nm}$ after $15 \mathrm{~min}$.

The scavenging activity was estimated based on the percentage of ABTS radicals scavenged by the following formula:

$$
\% \text { scavenging }=[(\mathrm{Ac}-\mathrm{As}) \div \mathrm{As}] \times 100
$$

Where-'Ac' is the absorption of control; 'As' is the absorption of tested extract solution.

\section{Statistical analysis}

All experiments were performed in triplicate and data were reported as mean \pm SD. The half-maximal inhibitory concentration $\left(\mathrm{IC}_{50}\right)$ value was calculated using the linear regression analysis.

\section{RESULTS AND DISCUSSION}

It is now an established fact that the free radical and reactive oxygen/nitrogen species become an important etiological factor in the pathogenesis of several diseases. Although, a number of antioxidants are available to reduce the risk/damage associated with the free radicals, but efficacy and safety of synthetic antioxidants is a matter of grave concern among scientists and is also an important current issue in the discovery of natural antioxidants [17]. Studies suggest that plant-derived bioactive constituents possessing antioxidant activity such as vitamins, alkaloids, tannins, terpenoids, phenolic compounds, flavonoids etc play a major role in the management of several diseases. Plant-derived herbal drugs have become a promising alternative to the available synthetic antioxidants.

\section{Percentage yields of different organic solvents extract of $M$. champaca leaves}

Extraction involves the use of an inert solvent which actively separates the molecules from the plant's parts. The extracts obtained with various solvents (Methanol, Ethanol, Hexane, and Chloroform) were weighed and their percentage yields were calculated as compared to the initial weight of the plant material, to get the extractive values. The present study revealed that the extraction yield of methanol (19.30\%) showed 
the highest value, followed by the yields of hexane (18.84\%), ethanol $(18.18 \%)$ and chloroform $(17.49 \%)$ The influence of nature of solvent and total time of extraction on the percentage extraction yield is shown in the fig. 1.

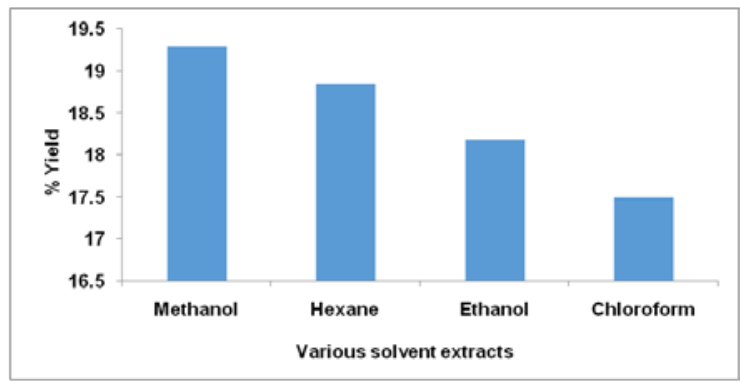

Fig. 1: Percentage yield of various solvent extracts of $M$. champaca (leaves)

\section{Phytochemical analysis}

The phytochemical screening was performed to identify the classes of chemical compounds present in the extracts. The Phytochemical screening test is of paramount importance in identifying a new source of a therapeutically and industrially valuable compound having medicinal significance, to make the best and judicious use of available natural wealth. Phytochemicals are naturally occurring primary and secondary compounds that are present in various plants to increase their medicinal value and used to fight various diseases. The phytochemical analysis of the plants is very important commercially and has great importance in pharmaceutical companies for the production of new drugs for curing various diseases. Phytochemicals are non-nutritive plant chemicals that have protective or disease preventive properties [18].

The phytochemical active compounds of $M$. champaca were qualitatively analysed from various extracts and the results are mentioned in table 1.

Table 1: Preliminary phytochemical tests of various solvent extracts of $M$. Champaca

\begin{tabular}{|c|c|c|c|c|}
\hline Phytochemicals group (test for) & MCME & MCETH & MCHE & MCCHLO \\
\hline Carbohydrates & + & + & + & + \\
\hline Reducing sugar & + & + & + & + \\
\hline Tannins & + & - & + & - \\
\hline Phenolic & + & + & + & + \\
\hline Flavonoids & + & + & + & + \\
\hline Lignin & + & - & + & - \\
\hline Amino acid & + & + & - & - \\
\hline Saponins & - & - & - & + \\
\hline Glycosides & + & - & - & - \\
\hline Sterols & + & - & + & + \\
\hline Triterpenes & + & + & - & - \\
\hline Alkaloids & + & + & + & + \\
\hline
\end{tabular}

(+) Presence of phytochemical compounds (-) absence of phytochemical compounds

Various extracts of $M$. champaca were screened for a total of 12 phytochemicals groups' viz. carbohydrates, reducing sugar, tannins, phenolics, flavonoids, lignins, amino acids, saponins, sterols, triterpenes, and alkaloids. The Methanol extract of $M$. champaca showed the presence of maximum phytochemicals (12), when compared to other solvent extracts viz. Methanol (11), Hexane (8), Ethanol (7), chloroform (7), thus inferring that methanol being a better solvent in this context because methanol extract is used to prepare the phenolic/antioxidant extract due to the fact that the methanol has a high dielectric constant/polarity and can be categorized as the most suitable extracting solvent.

The higher amount of such phytoconstituents, especially in methanol extracts of $M$. champaca leaves make it a strong free radical scavenger, indicating that this plant is a good source of natural antioxidants and can prevent free radical-mediated oxidative damage.

It is expected that the important phytochemicals recognized in our study will be very useful in curing various diseases of this region.

\section{Phenolic and flavonoid quantitative determination}

Phenolic compounds are naturally occurring substances in fruits, vegetables, nuts, seeds, flowers, herbs and beverages and an integral part of the human diet. Several studies have indicated that the antioxidant activities of some fruits and vegetables were highly correlated with their total phenolic contents. Antioxidants are compounds that can delay or inhibit the oxidation of lipids or other molecules by inhibiting the initiation or propagation of oxidative chain reactions. The antioxidant activity of phenolic compounds is mainly due to their redox properties, which can play an important role in absorbing and neutralizing free radicals, quenching singlet and triplet oxygen, or decomposing peroxides [19].

Flavonoids are a class of phenolic compounds ubiquitously found in plant parts like leaves, seeds, fruits, bark, and flowers. They are also called plant secondary metabolites and have a wide range of action including several pharmacological effects and other health benefits in humans on account of their different properties like antioxidant, anti-inflammatory, antiallergic, antimutagenic, antiviral, antineoplastic and antithrombotic. Regular intake of flavonoids has reduced the risk of acute as well as chronic diseases like cancer, inflammatory responses and cardiovascular diseases [20].

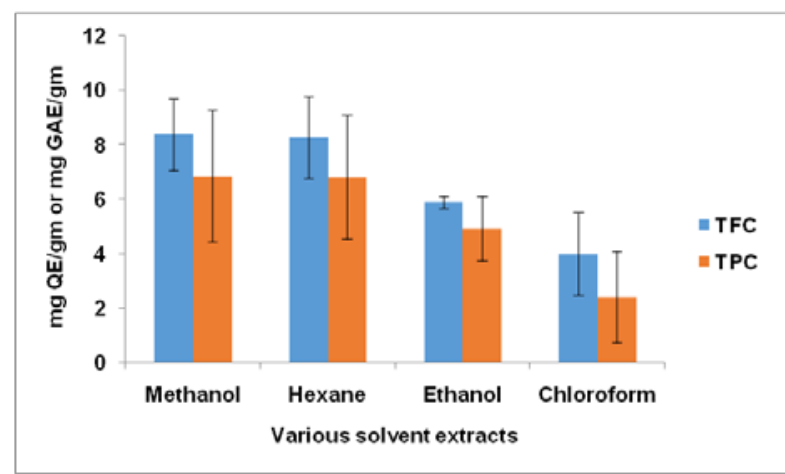

Fig. 2: Total flavonoid and total phenolic content of $M$. Champaca. Values expressed are mean \pm standard deviation $(n=3)$

In the determination of total phenolics and flavonoids, the results showed that the methanol solvent was better than other solvents to extract these compounds (fig. 2) which may be explained by its good polarity and solubility for phenolic compounds extracted from plants. The solvent with a low polarity such as chloroform showed much lower capacity for extracting phenolic and flavonoid compounds. The methanol 
extract contains highest amounts of both (TFC $8.39 \pm 1.31 \mathrm{mg} \mathrm{QE} / \mathrm{gm}$; TPC, $6.85 \pm 2.43 \mathrm{mg} \mathrm{GAE} / \mathrm{gm}$ ) followed by Hexane (TFC $8.27 \pm 1.49 \mathrm{mg}$ QE/gm; TPC, 6.82 $\pm 2.26 \mathrm{mg} \mathrm{GAE} / \mathrm{gm}$ ), followed by ethanol extract (TFC $5.9 \pm 0.23 \mathrm{mgQE} / \mathrm{gm} ; \mathrm{TPC}, 4.94 \pm 1.20 \mathrm{mgGAE} / \mathrm{gm})$ and least in Chloroform extracts (TFC $4 \mathrm{mg} \pm 1.52 \mathrm{QE} / \mathrm{gm}$; TPC, $2.41 \pm 1.67 \mathrm{mg}$ GAE/gm). Order of TFC and TPC among different solvents were in the order as Methanol $>$ Hexane $>$ Ethanol $>$ Chloroform.

Total phenolic and flavonoid content is an important factor in the consideration of antioxidant activity [21]. Therefore, the higher the value of both contents, the more beneficial the extract is to human health as they can quench (super-oxide) free radicals or primary oxidants.

Mascarenhas et al.(2017) observed that leaves contained maximum phytochemicals. Besides this, leaves are readily available in all stages of plants in comparison to seeds, which make them easier to be exploited for the same. Therefore, more detailed studies are needed to be carried out on leaves, also with regards to its quantitative estimation [22].

\section{Antioxidant activity (free radical scavenging activity of DPPH)}

DPPH assay has been extensively used for screening plant extracts because many samples can be accommodated in a short period and are sensitive enough to detect active ingredients at low concentration. The extracts containing a good amount of phenols and flavonoids possess potential antioxidant activity. Previous studies on other medicinal plants have also reported a positive correlation between phenolic and flavonoid content and DPPH radical scavenging activity of plant extracts [23].

The free radical scavenging activity of the various extracts of $M$. champaca leaves has been tested by DPPH radical method using Quercetin as a reference standard. The concentration ranged from $25-400 \mu \mathrm{g} / \mathrm{ml}$ (fig. 3). DPPH is a very stable free radical. In the case of Methanol extract and other extracts, $400 \mu \mathrm{g} / \mathrm{ml}$ concentration showed maximum DPPH radical scavenging activity followed by $200 \mu \mathrm{g} / \mathrm{ml}, 100 \mu \mathrm{g} / \mathrm{ml}, 50 \mu \mathrm{g} / \mathrm{ml}$ and $25 \mu \mathrm{g} / \mathrm{ml}$.

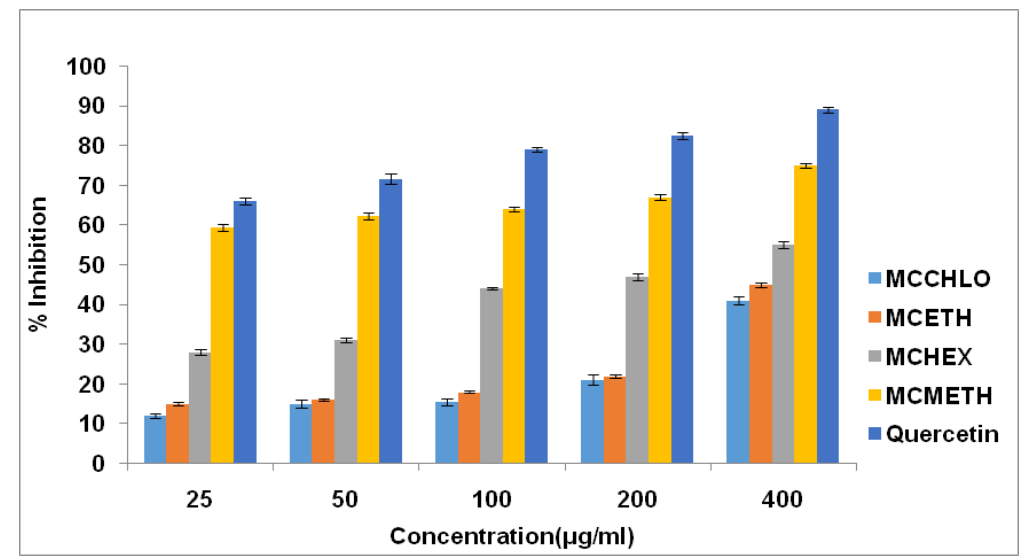

Fig. 3: DPPH radical scavenging activity of various solvent extracts, values expressed are mean \pm standard deviation $(n=3)$

The effect of antioxidants on DPPH radical scavenging is thought to be due to their hydrogen donating ability. The extent of decrease in the absorbance of DPPH in the presence of antioxidants correlates with the free radical scavenging potential of the antioxidant. Fig. 3 shows that both Quercetin and methanolic extract scavenged DPPH radicals in a dose-dependent manner, though by different capabilities. These scavenging activities are most probably and mostly due to the presence of various phenolic compounds.

The concentration of the sample at which the inhibition percentage reaches $50 \%$ is defined as the $\mathrm{IC}_{50}$ values thus $\mathrm{IC}_{50}$ values is defined as the concentration of substrate that causes $50 \%$ loss of the DPPH activity and was calculated by linear regression plots of percentage of antiradical activity against the concentration of the tested compounds.
Thus, $\mathrm{IC}_{50}$ values are negatively related to the antioxidant activity, the lower the IC $\mathrm{I}_{50}$ value, the higher the antioxidant activity of the tested sample and vice-versa. The radical scavenging activity and antioxidant potential of the plant extracts were determined by the ability of plant extracts to scavenge the stable free radical DPPH and convert into Diphenyl picryl hydrazine. The degree of decolourization from purple to yellow colour was measured spectrometrically at $517 \mathrm{~nm}$. The amounts of antioxidant activity present in various solvents were in the order of Methanol, Ethanol, Hexane, and Chloroform. The lowest $\mathrm{IC}_{50}$ value is $72.03 \pm 1.29 \mu \mathrm{g} / \mathrm{ml}$ was observed in Methanol extract and the highest $228.60 \pm 2.42 \mu \mathrm{g} / \mathrm{ml}$ in Chloroform extract. IC $\mathrm{I}_{50}$ values for Quercetin is $69 \pm 1.18 \mu \mathrm{g} / \mathrm{ml}$. IC 50 value was calculated by linear regression plots of the antiradical activity against the concentration of the tested compounds.

Table 2: IC $\mathrm{I}_{50}(\mu \mathrm{g} / \mathrm{ml})$ value of Quercetin and various solvent extract, values expressed are mean \pm standard deviation $(n=3)$

\begin{tabular}{lllll}
\hline Assay & MCMETH & MCHEX & MCETH & MCCHLO \\
\hline DPPH radical scavenging activity & $72.03 \pm 1.29$ & $100.79 \pm 0.82$ & $202.71 \pm 1.31$ & $228.6 \pm 2.42$ \\
\hline
\end{tabular}

Table 2 shows IC 50 values of $M$. champaca leaves extracts in various solvent in comparison to Quercetin (standard). The methanol extract of $M$. champaca exhibits significant activity with low $\mathrm{IC}_{50}$ value. $M$. champaca $\mathrm{IC}_{50}$ values varied from $72.03 \mu \mathrm{g} / \mathrm{ml}$ for the Methanol extract (the most active) to $100.79 \mu \mathrm{g} / \mathrm{ml}$ for the Hexane extract and $202.71 \mu \mathrm{g} / \mathrm{ml}$ for Ethanol extract to $228.60 \mu \mathrm{g} / \mathrm{ml}$ for the Chloroform extract (the least active). This indicated that Methanol extract has maximum, while Chloroform samples had least antioxidant activity and this analysis also reveal that there is a positive correlation between $\mathrm{IC}_{50}$ and total phenolic and flavonoids concentrate.

\section{ABTS radical scavenging activity}

The ABTS scavenging test is used to determine the antioxidant activity (by estimating peroxide formation) of both hydrophilic and hydrophobic compounds. The assay measures ABTS radical cation formation induced by metmyoglobin and hydrogen peroxide. The formation of the colour ABTS radical is suppressed by antioxidants by electron donation radical scavenging. The quantity of antioxidant in the test sample is inversely proportional to the ABTS radical development [24].

The ABTS radical cation is generated by the oxidation of ABTS with potassium persulfate, and its reduction in the presence of hydrogendonating antioxidants is measured spectrophotometrically at 734 $\mathrm{nm}$. This decolorisation assay measures the total antioxidant capacity in both lipophilic and hydrophilic substance. The effect of the antioxidant concentration and the duration of the inhibition of the radical cation's absorption are taken into account when the antioxidant activity is determined. 


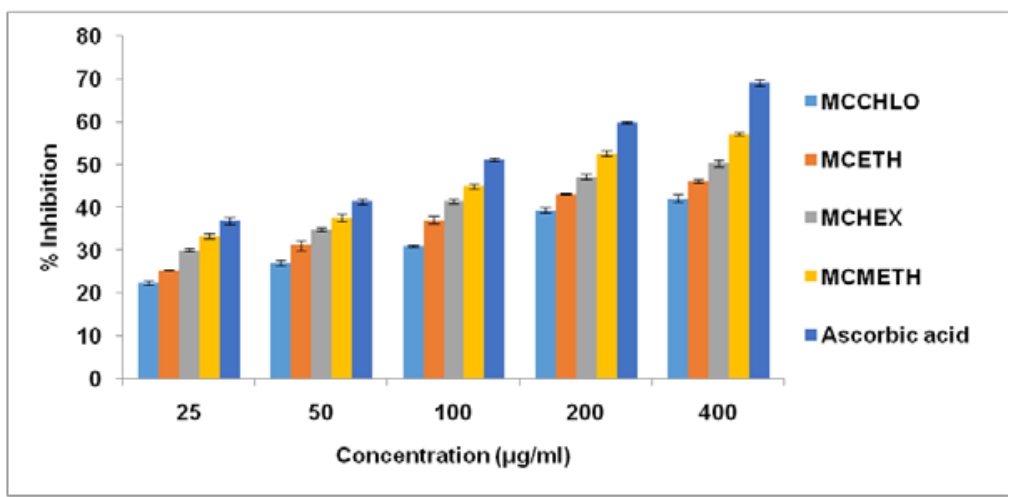

Fig. 4: ABTS radical scavenging activity of various solvent extracts, values expressed are mean \pm standard deviation $(n=3)$

Crude extracts of leaves of $M$. champaca are efficient free radical scavengers. The amount of Antioxidant potential present in solvents were in the order of Methanol $>$ Hexane $>$ Ethanol $>$ Chloroform. This indicated that Methanol extract had a maximum while, Chloroform samples had least antioxidant activity and this analysis also revealed that there is a positive correlation between $\mathrm{IC}_{50}$ and phenolic and flavonoids concentration. Fig. 4 shows the comparison of ABTS free radical scavenging activity of various extracts of $M$. champaca in comparison to Ascorbic acid (standard).
The $\mathrm{IC}_{50}$ values of these extracts (table 3 ) are also calculated to further evaluate the antioxidant activity. IC $\mathrm{I}_{50}$ values varied from $185.21 \pm 2.64 \mu \mathrm{g} / \mathrm{ml}$ for the Methanol extract (the most active) to $342.43 \pm 3.11 \mu \mathrm{g} / \mathrm{ml}$ for Hexane extract and $614.2 \pm 2.16 \mu \mathrm{g} / \mathrm{ml}$ for Ethanol extract to $710.96 \pm 0.24 \mu \mathrm{g} / \mathrm{ml}$ for Chloroform extract (the least active). Results for the assays of the antioxidative activity showed that $M$. champaca, MCMET extract has the ability to scavenge ABTS and DPPH radicals in a dose-dependent manner, to a much better extent than MCHEX, MCETH, and MCCHLO extracts.

Table3: $\mathrm{IC}_{50}(\mu \mathrm{g} / \mathrm{ml})$ value of ascorbic acid and various solvent extracts, values expressed are mean \pm standard deviation (n=3)

\begin{tabular}{|c|c|c|c|c|c|}
\hline Assay & MCMETH & MCHEX & MCETH & MCCHLO & Ascorbic acid \\
\hline ABTS radical scavenging activity & $185.21 \pm 2.64$ & $342.43 \pm 3.11$ & $614.2 \pm 2.16$ & $710.96 \pm 0.24$ & $111.15 \pm 1.81$ \\
\hline
\end{tabular}

The ABTS radical is reactive towards most antioxidants including phenolics, thiols, and Ascorbic acid. During this reaction, the blue ABTS radical cation is converted back to its colorless neutral form. The scavenging activity of ABTS radical by the leaves extract was found to be appreciable and this implies that the extracts may be useful for treating radical related pathological damage especially at limited concentrations [25]. The ABTS model can be used to assess the scavenging activity of both the polar and non-polar samples. The ABTS assay is based on the inhibition of the absorbance of the radical cation ABTS, which has a characteristic long wavelength absorption spectrum. The ABTS chemistry involves the direct generation of ABTS radical mono cation with no involvement of any intermediary radical.

\section{CONCLUSION}

The present investigation reports the estimation of the qualitative phytochemicals, total phenolics and flavonoids and the in vitro free radicals scavenging potential of various extracts of Michelia champaca leaves. The preliminary phytochemical screening revealed a rich number of phytoconstituents groups viz. flavonoids, alkaloids, tannins, glycosides, carbohydrates, amino acids, saponins, and phenolic compounds. Quantitative phytochemical analysis showed good amounts of phenolic and flavonoid contents and also exhibited significant in vitro antioxidant activity. A positive linear correlation between the antioxidant activities and the total phenolic and flavonoid contents of the plant extracts was observed. Study revealed variations in such reported activities due to different organic extraction solvents used. In overall conclusion, Michelia champaca has a good potential as a source of natural antioxidant for animal health and food industry and further relevant studies on similar lines would be worthwhile.

\section{ACKNOWLEDGMENT}

Authors acknowledge the Department of Biotechnology, MBGPG College Haldwani, Kumaun University (Nainital, Uttarakhand), for providing the necessary permission and facilities to carry out the research work.

\section{AUTHORS CONTRIBUTIONS}

All authors have equally contributed in the research work

\section{CONFLICT OF INTERESTS}

We declare that there were no conflicts of interest

\section{REFERENCES}

1. Pezzuto J, Taxol EJ. Production in plant cell culture comes of age. Nature Biotechnol 1996;1:1083.

2. Bhatt ID, Dauthal P, Rawat S, Gaira KS, Jugran A, Rawal RS, Dhar U. Characterization of essential oil composition, phenolic content, and antioxidant properties in wildand planted individuals of Michelia champaca jones. Sci Hort 2012;43:61-8.

3. Chopra RN, Nayar SL, Patel PJ. Glossary of Indian medicinal plants. Council of Scientific and Industrial; 1956. p. 89-4.

4. Perry LM. Medicinal plants of East and Southeast Asia: attributed properties and uses Cambridge, Massachusetts and London: The MIT Press; 1980. p. 154.

5. Barlow HS, Enoch IA, Rusell LRA. Tropical planting and gardening, Kuala Lumpur, Malayan Nature Society; 1991. p. 712.

6. Ambasta BP. The useful plant of India, publications and information directorate, CSIR New Delhi; 1994. p. 91.

7. Ahuja J, Suresh J, Deep A, Madhuri, Pratyusha, Ravi. Phytochemical screening of Aerial part of Artemisia parviflora Roxb: A medicinal plant. Der Pharm Lett 2011;3:116-24.

8. Ruwali P, Ambwani TK, Gautam P, Thapliyal A. Qualitative and quantitative phytochemical analysis of Artemisia indica willd. J Chem Pharm Res 2015;7:942-49.

9. Harborne JB. The flavonoids: advances in research. Chapman and Hall. London J Sci Food Agric 1973;3:90-103.

10. Singleton VL, Rossi JA. Colorimetry of total phenolics with phosphomolybdic-phosphotungstic acid reagent. Am J Enol Viticult 1965;16:144-58.

11. Zhishen J, Mengcheng T, Jianming W. The determination of flavonoid contents in mulberry and their scavenging effects on superoxide radicals. Food Chem 1999;65:555-9. 
12. Patel RM, Patel NJ. In vitro antioxidant activity of coumarin compounds by DPPH super oxide and nitric oxide free radical scavenging methods. J Adv Pharm Educ Res 2011;1:52-68.

13. Blois MS. Antioxidant determinations by the use of a stable free radical. Nature 1958;181:1199-200.

14. Ruwali P, Ambwani TK, Gautam P. In vitro antioxidative potential of Artemisia indica willd. Indian J Anim Sci 2017;87:1326-31.

15. Miller NJ, Evans RC, Paganga G. Antioxidant properties determined by ABTS radical assay. Free Radical Res 1997;26:195-9.

16. Re Raina AK, Perry. Antioxidant properties determined by ABTS radical assay. Free Radical Res 1999;26:195-9.

17. Karimi E, Oskoveian E, Hendra R, Jaafer HZE. Evaluation of Crocus sativus L. stigma phenolic and flavonoid compounds and its antioxidant activity. J Mole 2010;15:6244-56.

18. Krishnaiah D, Sarbatly R, Bono A. Phytochemical antioxidants for health and medicine: a move towards nature. Biotechnol Mol Biol Rev 2007;1:97-104.

19. Osawa T, Uritani I, Garcia VV, Mendeoza EM. Novel natural antioxidants for utilization in food and biological systems, postharvest biochemistry of plant food materialism the tropical, Tokyo, Japan, Japan Scientific Societies Press; 1994. p. 241-51.

20. Middleton EJR, Kandaswami C, Theoharides TC. The effects of plant flavonoids on mammalian cells: Implications for inflammation, Heart disease and cancer. Pharmacol Rev 2000;52:673-51.

21. Sreeja S, Raphael RK. Qualitative and quantitative phytochemical analysis and DPPH radical scavenging activity of different extracts of flower of Bauhinia acuminate linn. Int J Curr Pharm Res 2017;9:23-6.

22. Mascarenhas ME, Mandrekar CR, Marathe PB, Morais LJ. Phytochemical screening of selected species from convolvulaceae. Int J Curr Pharm Res 2017;9:94-7.

23. Shahidi F, Janitha PK, Wanasundara PD. Phenolic antioxidants. Crit Rev Food Sci Nutr 1992;32:67-103.

24. Andrade SE, Kahler KH, Frech F, Chan KA. Methods for evaluation of medication adherence and persistence using automated databases. Pharmacoepidemiol Drug Saf 2005;15:565-74.

25. Wang YG, Ellis N. Effect of individual variability on estimation of population parameters from length-frequency data. Can J Fish Aquat Sci 1998;55:2393-401. 